\title{
Movement, space and the logic of the gift: Reflections on Milbank and the African religious archive
}

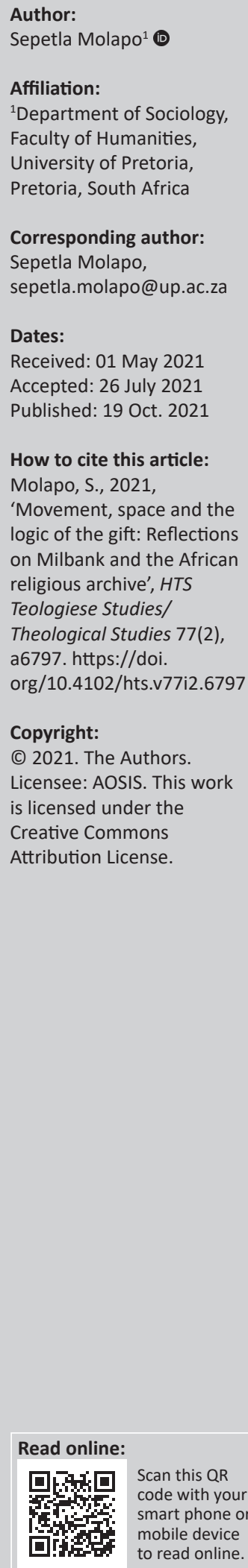

This article reflects on how the contemporary relationship between movement and space can be reversed so that movement regains priority over space in the experience of life. Its key argument is that movement has potential to take priority over space but only via the logic of the gift. The logic of the gift has potential to undermine the privilege colonial modernity accords to space over movement because its conception of exchange challenges exchange as a construct of economic logic central to the experience of modernity. The article focuses on the gift as is found in the work of John Milbank and the African religious archive. It tries to show that along with Milbank's imagination of the gift, the gift as a construct of the African religious archive stands to contribute in the fight against the continuing alienation brought about by the project of modernity. This is because it imagines the sacred dimension primarily via the terrain of the family.

Contribution: This article contributes to a reading of capitalism via the logic of the gift as a construct of the African religious archive and does so by borrowing from the work of theologians. In doing so, it tries to present a different way of thinking about gift giving in relation to the African religious expression, which has until the recent past been dominated by anthropologists.

Keywords: gift; community; space; movement; capitalism.

\section{Introduction}

The key concern of this article is the relationship between movement (understood as creative and barrier-breaking circulation and flow of human beings in their difference) and space (the ordered human geographies or territories) happening under conditions of the experience of modernity in South Africa after apartheid. The article asks how this relationship can be reorganised such that movement regains priority over space in the structuring of the experience of life. The article takes interest in this topic against a backdrop of the reversal, beginning with colonialism, of the relationship between movement and space in which case the latter gains priority over the former. This happens because economic logic drives the experience of colonialism and relies on race to realise its objectives. The reliance on economic logic and its accomplice, race delegitimises movement as what in the first place ought to constitute the organisation and experience of space. Beginning with colonial modernity, movement becomes important as far as it contributes to projects of utility. That is, it becomes significant as far as it aids capitalist adventures with the supply, for instance, of labour and raw materials. This dispenses with the historical place of movement as creative force and as what was at the heart of the experience of space in Africa. ${ }^{1}$

The question of the relationship between movement and space is of paramount importance to this article considering the failure of the post-apartheid dispensation to deliver community or coexistence apart from gates, enclosures, borders and securitisation because such co-existence has justice and the welcoming of the other and the stranger as its corner stone. This question is of significance because the end of apartheid and the dawn of democracy mark continuity with the logic of colonial modernity, which privileges space over movement in order to elevate race as a category informing social relations. The continuation of this logic of colonial modernity results partly from the coincidence of the dawn of democracy and South Africa's entry into global market liberalism. The latter is particularly important because transition to a global market dispensation

1.Movement as the force and as what comes before space is apparent in some accounts Christian missionaries furnish concerning the precolonial histories of the African communities they came to evangelise. See, for instance, Ellenberger's precolonial account of the Basotho (Ellenberger 1912). Historians also allude to this point in their critiques of African identities in post-independence African states (see Ranger 1985).

Note: Special Collection: Re-readings of Major Theorists of Religion: Continuities and Discontinuities, sub-edited by Mohammed (Auwais) Rafudeen (University of South Africa). 
marks at the same time an implicit acceptance of the practice of dealing with social problems via a logic of security. ${ }^{2}$ It is precisely this implicit acceptance of the logic of security as a mechanism appropriate for dealing with social problems that delivers a hollow democracy unable to reverse the inverse relationship between movement and space that colonial modernity inaugurates. The consequence of this is not only a deferment of what Derrida calls a democracy to come, but the continuing absence of community even after apartheid (Patton 2007). Put in other words, the reigning market ideology that deals with social problems via a logic of security postpones the problem of multiplicity that begins with colonial modernity in South Africa and the colonised world in general. This article directs its deliberations precisely to this problem.

In order to reflect on how the colonial relationship between movement and space can be reversed to realise movement as freedom and thereby deal with the problem of multiplicity, this article engages with the idea of the gift as found in the work of John Milbank and the African religious archive. It turns to Milbank and the African religious archive because it sees in both their conceptions of the gift, potential to address the problem of multiplicity that arises with the reversal of the relationship between movement and space. This is because the notion of gift evident in both these works transcend gift as a property of the self. Contra to Mauss (1954), gift in these instances is not what one would or could possibly give as one's possession. This is because it is always coloured with a sacred dimension exempting it from the character of ordinary gifts or social gifts. In both traditions, a true gift refuses possession and demands passage to the domains of others in order to carry out there the work of repair. The article shows, however, that, as found in Milbank, the application of the gift to the problem of multiplicity is rather limited by locating the sacred dimension primarily at the level of the church as a universal body of believers. It argues that this macro-level of exploration overlooks the family as terrain for encounter with the sacred dimension typical of the African religious expression. Consequently, Milbank ignores an important artery in a fight against the alienation brought about by capitalism.

\section{Colonial logic and the elevation of space in South Africa: A brief overview}

The reversal of the relationship between movement and space, in the history of South Africa, can be traced to three separate but interlinked developments. First, space takes priority over movement because the metaphysics accompanying both colonialism and apartheid assumes a dialectical conception of truth. In this metaphysics, truth is understood primarily in relation to victory over a non-European adversary. Truth no longer knows the metaphysics of participation (of finite will in

2.This point is crystal clear in the literature studying the phenomenon of gated communities in South Africa after apartheid (e.g. Hook \& Vrdoljak 2002; Junck 2017; Murray 2011). The article recognises that crime is a reality in South Africa, and does not suggest that individuals should not defend themselves against it. Its interest, not suggest that individuals should not defend thems
however, is in reading the implications of this defence. infinite will) that the modern episteme leaves behind beginning with the enlightenment (Milbank 2006). The consequence of delegitimisation of participation is the dissolution of dialogue as a potential terrain for the formulation of truth and as a terrain for meeting and encountering with the other. The dissolution of dialogue sets the stage for the articulation of politics as antagonism and hostility towards non-European others. It is this politics of antagonism and hostility that, among other things, gives priority of place to space over movement. This is because it sees in separation the very basis of relationality and this denies movement its role in the continuous making and remaking of space. Separation becomes a driving ideology because race and racism are concepts that are predominantly found in colonialism and apartheid. Separation demands keeping others with their difference outside the gates of the modern expression and experience of life. It is this gating of the modern experience and expression of life from threatening others, which imposes a direct attack on movement as what ought to inform the organisation of space. Separation is tied to space because it has to be gated and walled from non-European others. Space proclaims the beginning and end of boundaries between presumed enemies. This works against participation and movement, which presuppose the undermining of walls, gates, enclosures and borders. Participation and movement, as such, signal desire for reimagining humanity beyond the confines of modernity where the primary concern is with race. Spatial logic, or the use of space in order to uphold race as a defining feature in human social interactions, stands in the way of this endeavour. Overall, then, the spatial logic depicts the fixing in space of identities in line with modernity's fear of the other. Though not in direct relationship to South Africa, Said (1978), Mudimbe (1988) and Fanon (1990, 2008) individually explored this metaphysics which is underscored by the will to power that conquest and the missionary enterprise illustrate.

Secondly, space rises to prominence over movement because colonialism and apartheid, having gated the modern experience of life, deploy knowledge in order to produce subjects of conquest as having a form of humanity that is essentially different to that of Europeans ('as other than us'). In the South African context, this concern with the difference or otherness of colonised subjects is manifested, first, in colonial knowledge's target of the black body as a body exhibiting biological differences and as a body in possession of a lesser brain size compared to that of Europeans. This form of the production of difference is driven by eugenics and neuropsychiatry (Bertoldi 1998). The aim of this production of difference is to manufacture an inferior form of essence, which the black body, the body of the colonised subject, is supposed to exemplify. In the second instance, the production of colonised Africans as other than Europeans turns to the sphere of culture. The visible and apparent differences that human beings exhibit are seen to find expression in the domain of culture. Culture then becomes terrain for the maintenance and production of difference. This emphasis on culture as a source of difference finds 
emphasis in social anthropology, which furnishes apartheid with its own ideology (Bertoldi 1998:109). Here, the supposedly highly evolved cultures of European settlers are seen to be threatened by those of supposedly primitive colonised subjects who are still at the lower end of the evolutionary ladder. This threat on its own warrants distance and refusal of relationality with colonised subjects. Consequently, it makes restrictions on movement a necessary part of life. Apartheid's ideology of separate developments and of influx control illustrates precisely this point. It is an ideology born out of the fear of the priority of movement in the organisation of social and political life.

Thirdly, and flowing from above, because colonialism and apartheid produce the black body as a body of difference, they succeed in inaugurating a Manichaean logic to which this body of difference is both dispensable and indispensable (see Mbembe 2008). The dispensability and indispensability of the black body of difference to the Manichean world of both colonialism and apartheid become evident within the operations of capitalism. This body of difference is indispensable to this world because capitalism requires workers who can work for a pittance, without the benefit of full wages; and bodies designated as racially different become the apparent source for such workers. This then shows how, as Gilroy (1993) pointed out, the very idea of property and wealth under capitalism can never be fully understood without an appreciation of the existence of people who in many cases have had to, and continue to, work without the benefit of wages. The disposability of the black body of difference becomes apparent in that it is a body exposed to live under the harshest of circumstances. It is a body designated to inhabit death.

These three moments, outlined not so much in line with their chronological order or order of their significance, are important because they point to the genesis of enclosures and fortifications in South Africa. They illustrate how, as constructs of the modern colonial phenomenon, enclosures and fortifications arise in relation to the problem of the other. That is, confronted with the problem of multiplicity, the tendency of modern European thought has been to retreat into sameness. This retreat suggests a bifurcation in the very character of the project of modernity. On the one hand, modernity is about departure from particularities of traditional communities and the nation state in favour of a global perspective and experience. In this case, modernity alludes to a universal experience that cannot be imagined outside of encounter with others in their difference. On the other hand, it is defined by an unusual sense of fear of the other that calls for retreat from the same global perspective and experience. In this instance, the universal and global experience is cast as the domain of danger requiring security and is utterly devoid of a politics of disenclosure $^{3}$ (Kareka 2013:229; Mbembe 2019). This discourse has been historically prevalent, and continues on in our time to serve as the basis for the erection of enclosures and fortifications that are accompanied by technologies. The problem of the other, as a result, cannot be imagined outside of the working of the capitalist system. Capitalism, then and now, continues to profit from security risk assessments that often betray skin as the border.

\section{Milbank, community and the problem of multiplicity}

If colonial logic functions to privilege space over movement, and does so in a way that places race at the heart of human social relations, then how can the reversal of this relationship be achieved such that movement takes priority over space? This part of the article grapples with this question in relation to Milbank on his notion of the gift. It claims that Milbank's notion of the gift offers an opportunity to challenge the reversal by colonial logic of the relationship between movement and space because his notion of the gift imagines multiplicity via the logic of community (i.e. via a logic of diversity which stands opposed to the logic of uniformity characteristic of spatial logic). This directly offers a challenge to economic logic that is at the heart of the modern experience and organisation of space.

As found in the work of Milbank (1998, 2003), the logic of community is primarily concerned with thinking about the problem of multiplicity in the context of the modern experience of life. The logic of community is useful for this enterprise because, for Milbank, gift and relation are coincidental and this coincidence, he argued, is evident in the doctrine of creation and redemption (Billings 2005). Creation and redemption do not only speak of God's act of giving (the giving of the created world and that of the Son), but this giving already presupposes a relation (the relation of God to nature and humanity). The gift of God, that is, sets in motion community with God on the part of the created world and humanity. For Milbank, the modern experience of life is unable to address the problem of multiplicity because capitalism is central to the ways in which the modern experience of life finds articulation. The centrality of capitalism to the modern experience and expression of life makes the resolution of the problem of multiplicity almost impossible because the logic that drives capitalism is profit. This logic makes it difficult to address the problem of multiplicity because it arises out of a different form of the understanding of exchange. It arises out of the understanding of exchange as the exchange purely of commodities. That is, by giving capitalism a privileged position in the imagination of human social interaction, the modern expression of life surrenders social life to economic logic. This logic dispenses with the gift in favour of the commodity and expunges relationality of the social bonds that are necessary for the realisation of community (modernity's orientation towards formal impersonal contractual relations illustrates this point). Consequently, one of the key questions Milbank asks relates to how community as the expression of genuine bonds of movements are being restricted through the erection of walls and borders.
Globalisation, as such, does not meet the conditions of dis-enclosure. 
solidarity can be realised in order to deal with the problem of multiplicity.

In order to address this question, Milbank proposed that we should consider reality as given from an otherworldly beyond (i.e. we should take seriously the implications of the doctrine of creation). The consideration of reality as given introduces a different form of exchange centred around the gift as a modality organising social relations. The gift stands in sharp contrast to the commodity, which deprives relationality of genuine social bonds. If the commodity, operating via the logic of profit, implies alienation between human beings and nature, and amongst human beings themselves, then the gift seeks to repair the alienation and exploitation thrust upon life by the logic of profit. It seeks to put a stop to the endless process of the accumulation of wealth, which has become an end in itself. The gift tries to interrupt and disrupt exchange as the exchange purely of commodities and directs attention to exchange as the exchange also of genuine social bonds characterised by the circulation of gift in the ever-endless cycles of gratitude and obligation (Billings 2005). The gift as a result opposes the modern expression of life, which empties relationality of genuine social bonds necessary for the realisation of community. It opposes a life framed around the centrality of formal contracts that peripheralise informal social interactions. In modernity, the orientation to the life of contract chiefly finds expression in the market mechanism. This is because more than any other domain, it is in the market mechanism where the surrender of life to a system of means and ends finds articulation (Milbank 2003:165). The commodity, after all, as Marx pointed out, thrives in broken relations (Marx 1887).

By seeing reality as given from a beyond, Milbank tried to distinguish his gift-exchange from that of Mauss (1954) which is derived from the social domain. The problem with socially derived gifts is, he argued, that they lack an 'unknown variation' (i.e. those who gave them are known) and consequently, they are without a sacred dimension that gifts must have if they are ever to become gifts at all (Milbank 1998:48). Socially derived gifts lack a sacred dimension because those who give them are known. While those who give them may set in motion a gift-exchange tying neighbours in relationships of obligation, such relationships work precisely with a model that assumes neighbours. It is a model that is oblivious to strangers who may in some cases be made neighbours through violence. Socially derived gifts consequently are unable to move into the domain of strangers except through a process of turning the stranger into the same. They are not fully able to acknowledge the stranger in their strangeness unless the singularity of the stranger is denied in a process that makes the stranger like one of them. In the ultimate end, they are unable to facilitate the experience of transcendence precisely because they lack an unknown variation.

From his conception of gift, Milbank is able to draw some lessons that are of significance for the problem of multiplicity.
Firstly, if reality is given from an otherworldly beyond then it bears the resemblance of the giver in much the same way that Mauss' gifts deriving from the social domain resemble the character of the giver. The giver is in the gift - which in this case - is reality itself. The claim that the gift resembles the giver is of paramount importance for the problem of multiplicity. This is because if indeed the gift resembles the giver, then the astonishing breadth of diversity and difference we see in the world points to the character of the giver. It declares the giver's choice to manifest only in the form of difference. Difference thus inaugurates and serves as the very basis of the manifestation of the giver. The giver cannot be known except via the prism of difference 'mediated by local pathways' (Milbank 1998:53). That is, there is no way of knowing the giver except through the diversity of perspectives necessitated by the sheer existence of difference in the world. This is because if the claim that the giver is in the gift is true, then the difference in the world is worthy of celebration because it is a manifestation of the diversity of the giver. If the giver is in the gift then everything that is created has value and integrity by virtue of its sheer existence in the world. The implications for a different relationship with planet earth that stays clear of a relationship of exploitation are clear here.

In the end, for Milbank, church, understood as a universal body of believers, is itself the gift of community to the world (Milbank 2003:ix). It is, as such, the terrain for the restoration of community that the elevation of the commodity over the gift in the modern era seeks to dispense with. Consequently, church is the domain for the possible resolution of the problem of multiplicity, which the elevation of economic logic in the modern dispensation exacerbates. Church has this privileged position because it is the sphere for the realisation of the gift of the Son that manifests in its transnational and trans-ethnic character and finds concrete expression via the Eucharist (Milbank 2003:105). It is the space for breaking down barriers that come about because of submission to economic logic common to the modern era. This submission is evident in the elevation of the commodity over the gift and in the valorisation of formal contractual relations over informal and personal relations. Because as gift of community to the world, church holds the possibility of resolving the problem of multiplicity and overcoming barriers of difference, precisely because it holds potential to overcome life surrendered to the authority of the commodity, it presents the possibility of overcoming the centrality of the logic of security that is apparent to modern human social interactions. As a gift of community to the world, the church does not only address the problem of multiplicity but also the problem of elevation of space over movement. This is because space derives its priority over movement out of the elevation of economic logic as what must shape human social interactions. The logic that elevates space over movement is the logic of the commodity. It is the logic of capitalism, which the circulation of the gift in cycles of gratitude and obligation seeks to overcome. 


\section{The gift of obligation: A critical engagement with Milbank}

While Milbank's thinking has potential to respond to the problem of multiplicity and consequently of the privileging of space over movement, its chief problem is that its imagination of the sacred nature of the gift bypasses the family in favour of the church as a universal and catholic body of believers. It overlooks an institution that plays a crucial role to many religions of the family and the clan such as indigenous African religions. The consequence of this is that its imagination of confrontation with the alienating tendencies of capitalism is situated at the macro level of society ignoring its micro. Consequently, it leaves out domain that is of critical importance in confronting the alienation brought about by capitalism. The task of imagining the gift as potential terrain for challenging the dominance of economic logic and its subsequent reordering of the relationship between movement and space in line with the dictates of colonial logic must depart from recognition that the prior terrain for thinking about the sacred dimension is the family. It is only when we return the conversation about the sacred nature of the gift back to the domain of the family, we are better positioned to challenge the alienation brought about by capitalism. This part of the article draws from the African religious archive to not only try to engage Milbank on the gift, but it also seeks to point to the family as the potential sphere for confronting the dominance of economic logic to the modern experience of life. This section's reflections are drawn from the African religious archive as found in the works of Mbiti (1989, 2012) and Setiloane (1976, 1986). However, as far as possible, this section stays away from the Christian theological lens that informs this scholarship.

While for Milbank, the Christian notion of the gift rests primarily on God's gift of the Son who unveils the gift of the Holy Spirit and of Grace that founds the community of believers (i.e. the church), the African religious archive positions the gift as a product primarily of loss. The gift in this case cannot be understood apart from the ancestors who function as guardians of the morality and life of the family and the clan (Setiloane 1976). In this instance, the gift arises out of the loss through death of loved ones who by virtue of that death comprise the realm of the sacred dimension. The return of the loved ones to familial relations (as ancestors) inaugurates life as a gift. This is because the return of these loved ones to familial relations (often via the medium of the dream) is at the same time a return to relations of obligation. The ancestors return to remind and to rekindle relations of obligation among familial relationships. This obligation, which serves as a conduit for the exchange of solidarity, is due to both the living and the departed loved ones (i.e. the dead). Obligation as a result serves as the cornerstone of familial relations and is a true and genuine gift precisely because it arises out of a sacred dimension. What makes obligation a true gift is precisely its connection with the sacred dimension (i.e. obligation arises out of a world of those taken by death). As a gift, therefore, obligation is a product of loss (i.e. the loss of loved ones to death). It is tied to the circulation of loss without which it is impossible to comprehend and cannot be a gift. Consequently, loss extends obligation as a gift and distinguishes it from social gifts that may function to reproduce existing hierarchies. This is a point that those who argue that ancestors reinforce existing social hierarchies, miss (Mageza 1997). They miss the gift as the terrain for exiting limiting and oppressive experiences of life precisely because its connection with loss accords it with transcendence. It is precisely because it is a gift that it carries the potential to be rejected in much the same way as the gift of the Son was and still is being rejected by some today. The gift of obligation is a free gift and must be accepted freely.

To say that obligation is a true and genuine gift around which relationality arises, has implications for Milbank's work. This is, because as a construct of the African religious archive, gift gives rise to a different idea of exchange. In this case, exchange emerges as the exchange of obligation with a kin. It is obligation that gives rise to solidarity and community. This is to say that the first terrain of the expression of community is the family. The family and kinship relations are to the African religious archive what church as a gift of community to the world is to Christianity. There is no way, in this case, of speaking about the sacred dimension without the family and kinship relations, which mediate its manifestation around the gift of obligation. The centrality of the family to the African religious expression confronts capitalism with its individualism. This is to say that an awakening of consciousness in a fight with capitalism must realise the significance of the family and kinship relations as a primary point of departure in counter capitalism imaginations. This awakening is necessary given Christianity's delegitimisation of the African expression of spirituality beginning with colonialism. Such delegitimisation has aided the cause and triumph of individualism and capitalism in Africa and the world. Christianity, that is, has assisted colonial modernity's project of dismantling the sacred domain, facilitating the expression of community - the family. A reimagining of confrontation with capitalism must necessarily renew kinship relations and see them as a vehicle for challenging the project of modernity epitomised by the valorisation of capitalist relations. It is true, of course, that as a construct of the African religious expression, the family is the terrain for problematic social relations epitomised by the operations of patriarchy. Patriarchal relations are, of course, manifested in any given religion. However, it is precisely to these problematic relations that the gift of obligation addresses itself. The gift returns to demand exit from limits and limiting or oppressive arrangements. It returns to demand renewal of the social life and experience. Where there exists a sterile repetition of the reproduction of the social hierarchy, it is because the connection of the gift of obligation to loss is not fully grasped.

Now, it is true that Milbank is concerned with the defence of the family and locality, which he argued, have come under the onslaught of capitalist exploitation (Milbank 2003:166). This article's argument, however, is that his theory is not able to speak to the specificity of the family as a sacred domain in 
its own right. Family in Milbank's terms is the church (the universal body of believers). Membership of this family nonetheless presupposes conversion to Christianity or the acceptance of the gift of the Son. It is not a family to which one belongs by virtue of blood relations. This article seeks to highlight the significance of familial (or blood relations) as a terrain for the expression of the sacred dimension, which Milbank and Christianity at large simply ignore. This is despite the fact that the body and blood are important components of the Christian discourse. This significance, of course, manifests in relation to the body and blood of the Son. The African religious expression is a call to the recognition of the sacred nature of the body and blood of kin as vehicles for the exchange of obligation and therefore of community. It is a rebuke to both Christianity and capitalism as far as the former treats only the body and blood of the Son as sacred and of the latter's consignment of the body to the realm of the mundane. A genuine confrontation with economic logic must begin with the recognition of the body and blood of kin as sacred and as setting in motion obligation as a liberating gift. Real confrontation with economic logic must begin in the family and specifically, must make patriarchy a target. This is because capitalism thrives also on the devaluing of women's lives. So, while Milbank pays attention to the problem of multiplicity, a focus on the family by the African religious expression directs attention to the deeply problematic relations that patriarchy inaugurates and how this nourishes capitalism.

The family, however, is not necessarily the sole destination of obligation. It is rather a medium through which obligation passes to the domain of others and strangers. This passage of obligation is signalled by the special reference given to the ones other than ancestors (i.e. the figures of God). These are those who cannot and never will be available to memory and recollection as is the case with ancestors. Consequently, their unavailability to memory suggests a different form of loss to that implied by the ancestors (see Molapo 2021). This is a primordial form of loss without return. It can never return because it is unable to have intimacy with memory. It is a form of loss nonetheless, without which the intimacy of memory and loss is impossible. That is, it is a form of loss that makes the return of loved ones lost to death possible in the first place. Without this form of loss, the sacred character of the family is impossible. It is a form of loss that accords the sacred domain with its own condition of possibility. Because it can never know intimacy with memory, this form of loss directs obligation to alienation. It takes it directly to the realm of those who are not family - the domain of others and strangers. If we recognise the abuse, suffering and pain that being others and strangers often implies, then the crossing of obligation from family to others and strangers is of paramount importance. This is particularly true of those others and strangers who have been made so by the modern paradigm that capitalist social relations exhibit. The call is to inhabit, along with them, those spaces and experiences of alienation that have been rendered so by the elevation of the commodity over the gift. In this case, the elevation of the commodity over the gift points to how the celebration of the division between the body and spirit (characteristic of modernity) has deligitimised the sacred domain of family. We inhabit those spaces in order to repair the social relations undermined by capitalism. This is what obligation seeks to achieve at any given time - the repair of social relations so as to realise community.

Milbank, following Marx, certainly recognises the problematic nature of the alienation brought about by capitalist social relations on modern life. Of course, he departs from Marx as far as Marx envisages the subjugation of exchange in communism. The subjugation of exchange is flawed because it betrays how Marx considers community as a product of the utility of reason and not as an end in itself. For Milbank, the collective is always born of exchange and this is why he takes issue with Marx's subjugation of exchange to the collective in communism. What this article senses in Milbank though is a lack of clear politics directed at the alienating characteristic of modern life. He deals with the fact of alienation in modern life through a process that romanticises the Thomistic Christianity of the medieval period. Confronted with the alienation characteristic of modern life, Milbank looks back to an apparent glorious Christian past in order to recover there a Christian practice with potential to deal with the contemporary alienation brought about by capitalism. This approach is of course emblematic of Western European thought in general. Confronted with the alienation of modernity, Western European thought tends to look back to a time when alienation was apparently not a problem (Nancy 1991). That is, it tends to be nostalgic. This nostalgia is a problem in the way Milbank deals with the alienation characteristic of the modern life. This nostalgic manner of dealing with alienation suggests that church as a gift of community to the world existed sometime in the past and is now lost and must be rediscovered. It suggests that in its contemporary manifestation, the church is not adequately prepared to deal with the challenges posed by modern life nor does it give the impression that as a construct of Christianity, the destination of the gift is alienation. This contrasts sharply with the African expression of religion, which sees alienation as the destination of gift. The repair of social relations at any given point is what religion must undertake. Concerning this article, that repair must occur under conditions of modern life. Consequently, while Milbank offers a penetrating critique of exchange as a construct of capitalism, his notion of exchange suffers from nostalgia for the good old Christian days in which Christians knew how to deal with the alienation of the market. What is also not clear is how Milbank's project will succeed given the post-Christian nature of Europe.

\section{Conclusion}

This article has tried to use the thinking of John Milbank and the African religious archive on the gift and has done so in order to reflect on the contemporary relationship between movement and space. The claim of the article is that the contemporary relationship between movement and space has its roots in colonial logic that privileges the latter over the former. This happens because economic logic, which is the 
driving force behind colonial experience, is primarily a logic of uniformity. It is a logic that dispenses with difference and diversity in favour of what is held in common. This orientation towards the common and the uniform opens room for the elevation of race as a force informing human social interactions. It leads to the gating of the modern experience of life such that those considered different are locked outside these gates and dealt with through the logic of security.

The article has shown that this privileging of space over movement, which begins with the colonial encounter, can be challenged via the logic of the gift such that movement regains priority over space in the experience of life. Using Milbank and the African religious archive, it has illustrated that economic logic (or the logic of space) can be challenged via the logic of the gift because the logic of the gift is the logic of community. Consequently, because the logic of the gift is the logic of community, it is the logic that has difference and diversity as its cornerstones. To experience community after all is to embark on a gift-exchange with others in their difference. It is precisely because the logic of the gift is the logic of community that it stands in sharp contrast to the economic logic that the colonial encounter inaugurates.

However, the article has argued that locating the sacred nature of the gift within the context of the family unveils another pathway by which the contemporary dominance of economic logic and of the privileging of space over movement can be challenged. This is because family does not only open our eyes to the significance of solidarity with kin, but it also opens up space for the gift to deal with the deeply problematic gendered relations upon which capitalism thrives. The gift of obligation is both invitation and demand for renewal as well as the realisation of freedom. It has less to do with the reproduction of problematic social relations. Imagining the gift of obligation as terrain of freedom opens up possible alliances between the African religious archive and Milbank's radical orthodoxy. However, in the true spirit of participation, this alliance against the alienating forces of contemporary modern life must be characterised by difference in styles of thought and strategy around how the battle against this alienation is to be fought.

\section{Acknowledgements Competing interests}

The author declares that he has no financial or personal relationships that may have inappropriately influenced him in writing this article.

\section{Author's contributions}

S.M. is the sole author of this article.

\section{Ethical considerations}

This article followed all ethical standards for research without direct contact with human or animal subjects.

\section{Funding information}

This research received no specific grant from any funding agency in the public, commercial, or not-for-profit sectors.

\section{Data availability}

Data sharing is not applicable to this article as no new data were created or analysed in this study.

\section{Disclaimer}

The views and opinions expressed in this article are those of the author and do not necessarily reflect the official policy or position of any affiliated agency of the author.

\section{References}

Bertoldi, A., 1998, 'Oedipus in (South) Africa?: Psychoanalysis and the politics of difference', American Imago 55(1), 101-134.

Billings, J.T., 2005, 'John Milbank's theology of the gift and Calvin's theology of grace', Modern Theology 21(1), 87-105. https://doi.org/10.1111/j.1468-0025.2005.00276.x

Ellenberger, D.F., 1912, A history of the Basuto: Ancient and modern, Morija Sesuto Book Depot, Morija.

Fanon, F., 1990, The wretched of the earth, Penguin Books, London.

Fanon, F., 2008, Black skins, white masks, transl. C. Lam Markmann, Grove Press, New York, NY

Giddens, A., 2003, Runaway world: How globalization is reshaping our lives, Routledge, New York, NY.

Gilroy, P., 1993, The black Atlantic: Modernity and double consciousness, Verso, London \& New York, NY.

Hook, D. \& Vrdoljak, M., 2002, 'Gated communities, heterotopia and a "rights" of privilege: A heterotopology of the South African security park', Geoforum 33, 159-219. https://doi.org/10.1016/S0016-7185(01)00039-2

Junck, L., 2017, 'Fenced off: Suspicion and the city as an exclusive space in postapartheid, suburban Cape Town', CODESRIA Bulletin Nos 3 \& 4, pp. 14-17, viewed n.d., from https://www.scribd.com/document/485851844/CODESRIA-BulletinNumber-3-4-2017.

Kareka, A., 2013, 'Writing Africa into the world and writing the world from Africa: Mbembe's politics of Dis-enclosure', Critical Philosophy of Race 1(2), 228-241. https://doi.org/10.5325/critphilrace.1.2.0228

Mageza, L., 1997, African religion: The moral traditions of abundant life, Orbis Books, New York, NY.

Mauss, M., 1954, The gift: Forms and functions of exchange in archaic societies, Routledge, London.

Marx, K., 1887, Capital: A critique of political economy (Volume 1), Progress Publishers, Moscow.

Mbembe, A., 2008, 'The aesthetics of superfluity', in S. Nutall \& A. Mbembe (eds.), Johannesburg: The elusive metropolitan, pp. 37-67, Wits University Press, Johannesburg.

Mbembe, A., 2019, Out of the dark night: Essays on decolonization, Columbia University Press, New York, NY.

Mbiti, J., 1989, African religions and philosophy, Heinemann, Oxford.

Mbiti, J., 2012, Concepts of God in Africa, Acton Press, Nairobi.

Milbank, J., 1998, 'The politics of time: Community, Gift and Liturgy', Telos (113), 41-67.

Milbank, J., 2003, Being reconciled: Ontology and pardon, Routledge, London.

Milbank, J., 2006, Theology and social theory: Beyond secular reason, Blackwell Publishers, Oxford

Molapo, S., 2021, 'Lost to presence: The entanglements of writing, Protestant Christianity and empire in 19th century Southern Africa', Journal for the Study of Religion 34(1), 1-20.

Mudimbe, Y.V., 1988, The invention of Africa: Gnosis, philosophy and the order of knowledge, Indiana University Press, Bloomington, IN.

Murray, M., 2011, City of extremes: The spatial politics of Johannesburg, Duke University Press, Durham.

Nancy, J.L., 1991, The inoperative community, University of Minnesota Press, Minneapolis, MN.

Patton, P., 2007, 'Derrida, politics and democracy to come', Philosophy Compass 2(6), 766-780. https://doi.org/10.1111/j.1747-9991.2007.00098.x

Ranger, T., 1985, The invention of tribalism in Zimbabwe, Mambo Press, Gweru.

Said, E., 1978, Orientalism, Penguin Books, London.

Setiloane, G.M., 1976, The image of God among the Sotho-Tswana, Balkema, Rotterdam. Setiloane, G.M., 1986, African theology: An introduction, Skotaville Publishers, Johannesburg. 